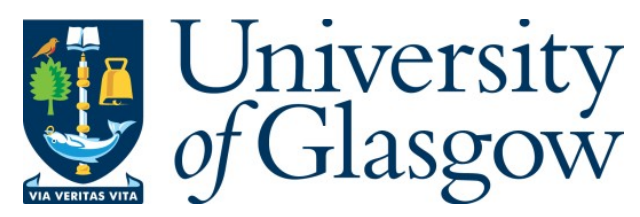

Taylor, R. S., Dibben, G., Faulkner, J. and Dalal, H. (2021) More evidence of cardiac rehabilitation: need to consider patient quality of life. Canadian Journal of Cardiology, 37(10), pp. 1681-1682.

(doi: 10.1016/j.cjca.2021.01.012)

This is the Author Accepted Manuscript.

There may be differences between this version and the published version. You are advised to consult the publisher's version if you wish to cite from it.

https://eprints.gla.ac.uk/233202/

Deposited on: 4 February 2021

Enlighten - Research publications by members of the University of Glasgow http://eprints.gla.ac.uk 


\section{More evidence of cardiac rehabilitation: need to consider patient quality of life}

To the editor:

We congratulate Huang and colleagues on their network meta-analysis of randomised controlled trials looking at the effectiveness of cardiac rehabilitation for people with a confirmed diagnosis of coronary heart disease (CHD) recently published in the journal [1]. This is certainly one of the most comprehensive published reviews in this field to date. As authors of the Cochrane review of cardiac rehabilitation for CHD, we note that the findings of this study by Huang et al are consistent with our systematic review and metaanalysis published in 2016 [2]. Both reviews show that rehabilitation reduces the risk of hospitalisation but that there is no strong evidence that it offers benefit in terms of all-cause mortality or risk of cardiovascular events including myocardial infarction or revascularisation. Furthermore, as with our meta-regression analyses in our 2016 Cochrane review, there is no strong evidence to differentiate the relative benefits of cardiac rehabilitation whether delivered as exercise-only intervention or a comprehensive intervention i.e., exercise alongside psychoeducational interventions. Despite this absence of strong evidence of added value of comprehensive rehabilitation, international guidance, including the Canadian Association of Cardiac Rehabilitation clinical guidelines support comprehensive programmes [3]. Contrary to Huang and colleagues' comment, the funnel plot analysis and Egger statistical tests did not show publication bias in our 2016 Cochrane review.

Although a robust statistical analysis and an important contribution to the literature, the Huang meta-analysis does not include health-related quality of life. We believe this is an important omission as quality of life is increasingly recognised as a key outcome for patients with CHD [4]. Patient participation in cardiac rehabilitation is often driven by a desire to improve their health-related quality of life over and above the prognostic benefits of adhering to their lifestyle risk factor modification and drug therapy. At the end of 2020, we updated our Cochrane analysis (searches to March 2020) so that now includes 80 randomised controlled trials in 22,469 CHD patients. Meta-analysis from our 2020 update review shows that participation in cardiac rehabilitation is indeed associated with an improvement in healthrelated quality compared to usual care (see Figure 1). However, only 29 (36\%) included trials reported validated health-related quality of life indicates the continued importance in future trials in including this outcome.

Rod Taylor MSc PhD, Grace Dibben PhD, James Faulkner PhD, Hasnain Dalal MBChB, MD rod.taylor@glasgow.ac.uk

MRC/CSO Social and Public Health Sciences Unit \& Robertson Centre for Biostatistics, Institute of Health and Well Being, University of Glasgow, Glasgow, UK 
Funding Sources: the authors have no funding sources to declare

Disclosures: the authors have no conflict of interest

\section{References}

1. Huang R, Palmer SC, Cao Y, Zhang H, Sun Y, Su W, Liang L, Wang S, Wang Y, Xu Y, Melgiri ND, Jiang L, Strippoli GFM, Li X. Cardiac Rehabilitation Programs for Chronic Heart Disease: A Bayesian Network Meta-analysis. Can J Cardiol. 2020 Epub ahead of print.

2. Anderson L, Thompson DR, Oldridge N, Zwisler AD, Rees K, Martin N, Taylor RS. Exercise-based cardiac rehabilitation for coronary heart disease. Cochrane Database Syst Rev. 2016;2016(1):CD001800.

3. Canadian Guidelines for Cardiac Rehabilitation and Cardiovascular Disease Prevention: Translating Knowledge into Action, 3rd Edition, Canadian Association of Cardiovascular Prevention and Rehabilitation (CACPR). March 2009. https://cacpr.ca/Guidelines (last accessed 22nd December 2020).

4. Dalal HM, Taylor RS, Doherty P. Heart failure rehabilitation improves quality of life but we need to offer alternative modes of delivery to increase uptake. Eur J Prev Cardiol. 2020;27:2047-2048. 
Figure 1. Impact of exercise-based cardiac rehabilitation on health-related quality of life

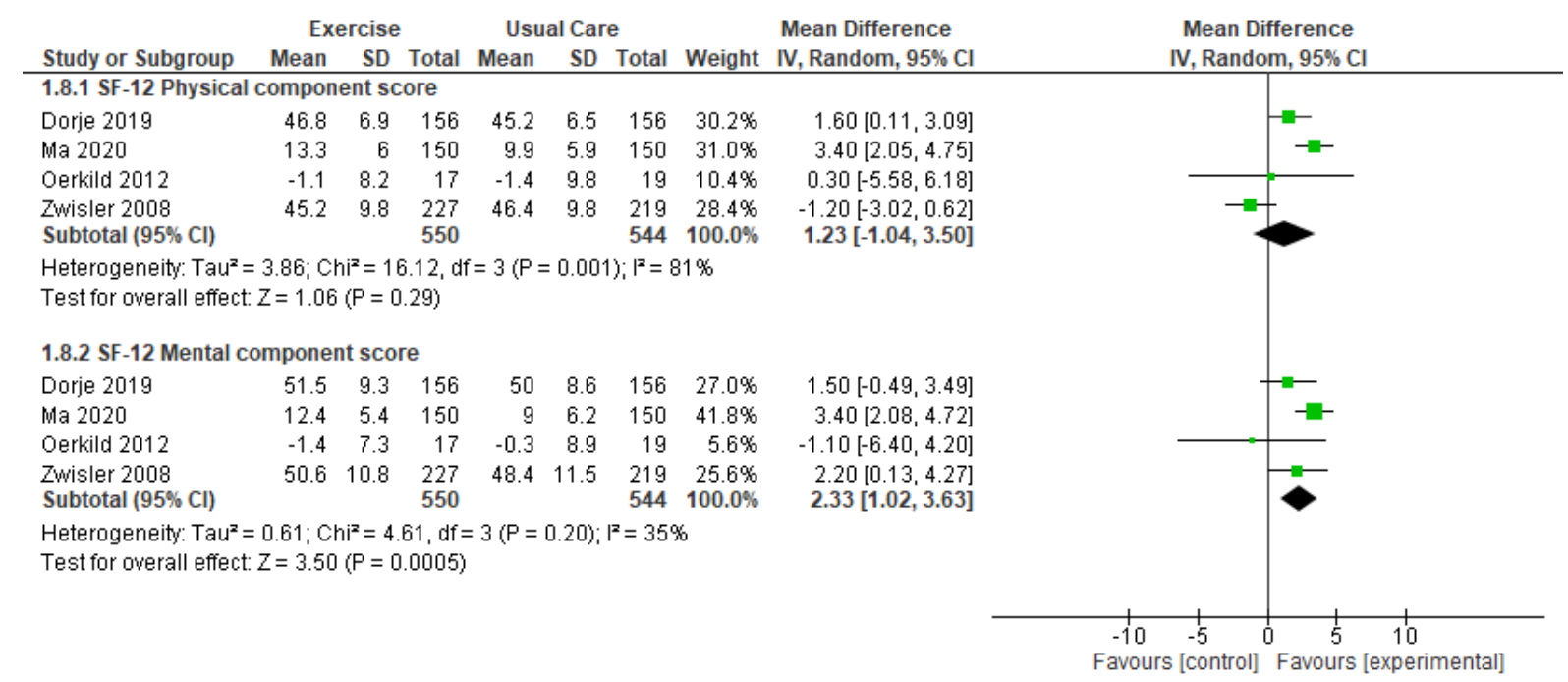

